\title{
Coordination Polymerization in Water Affording Amorphous Polyethylenes
}

\author{
Anke Held and Stefan Mecking*[a]
}

\begin{abstract}
The coordination polymerization of ethylene in water as a reaction medium was studied. Rubbery amorphous branched polyethylene was obtained when a known cationic diiminesubstituted methyl complex was employed as a catalyst precursor. High rates of up to $900 \mathrm{TOh}^{-1}$ (turnover frequency) were observed. In contrast to solution polymerization in an organic solvent, the rate of suspension polymerization in water increases greatly with ethylene pressure in the range up to 20 bar; this indicates control of the polymerization rate by the concentration of the olefin monomer at the catalytically active site. The effect and
\end{abstract}

mode of mass transfer phenomena were studied. A high catalyst stability in the aqueous coordination polymerization was observed. It was found to be due to an "encapsulation" of the waterinsoluble catalyst precursor in the hydrophobic amorphous polymer during the polymerization reaction, and this resulted in strongly restricted accessibility for the aqueous phase. Surprisingly, exposure of the water-stable catalyst precursor to ethylene monomer in so-

Keywords: branched polyethylene • ethylene $\cdot$ palladium $\cdot$ polymerizations - water chemistry lution in the presence of water resulted in immediate decomposition. Polymer microstructure, and thermal and mechanical properties were investigated. The different degree of branching, molecular weight, and corresponding macroscopic properties of the polymers obtained in water as a reaction medium versus solution polymerization in methylene chloride under the same conditions are due to the different phase behavior during polymerization (suspension vs. solution), as opposed to an effect of water on the catalytically active centers.

\section{Introduction}

Water possesses unique properties as a reaction medium. It is highly polar and immiscible with most organic compounds, has a high heat capacity, and also has a strong propensity for micelle formation. In addition, water is an ideal medium from an environmental and safety perspective. Thus, emulsion and suspension polymerization of olefinic monomers are employed on a vast scale, for example, for the direct production of water-based latices, used for coatings and paints. ${ }^{[1]}$ In contrast to these free-radical polymerizations, transition metal catalyzed coordination polymerization reactions in water have received less attention, as the early transition metal catalysts ${ }^{[2]}$ used for commercial polyolefin production are extremely sensitive to moisture. Running such polymerizations in aqueous emulsion or suspension is a highly attractive goal however, as many polymer microstructures are not available by other means than coordination polymerization.

[a] Dr. S. Mecking, Dipl.-Chem. A. Held Institut für Makromolekulare Chemie und Freiburger Materialforschungszentrum der Albert-Ludwigs-Universität Freiburg

Stefan-Meier-Strasse 31, 79104 Freiburg (Germany)

Fax: (+49) 761-203-6319

E-mail: mecking@uni-freiburg.de
Late transition metal complexes are generally less sensitive to polar media as a result of their less oxophilic nature. With late transition metal catalyzed $\mathrm{C}-\mathrm{C}$ linkage of ethylene in general (i.e. in organic reaction media), dimers or oligomers are obtained usually due to the propensity of late transition metal alkyl complexes for $\beta$-hydride elimination. ${ }^{[3]}$ Only a limited number of catalysts for the polymerization to high molecular weight products are known. Most of them are based either on neutral nickel(II) complexes (exemplified by structures $\mathbf{1}$ and 2, Figure 1) ${ }^{[4]}$ of formally monoanionic bidentate ligands or on cationic iron, cobalt, nickel, or palladium complexes $(\mathbf{3}, \mathbf{4})^{[5]}$ of neutral multidentate ligands with bulky substituted nitrogen donor atoms. ${ }^{[6]}$

The recent discovery of catalysts based on structures $\mathbf{2}, \mathbf{3}$, and $\mathbf{4}$ has spurred an intense search for late transition metal olefin polymerization catalysts based on other ligand structures, and high-throughput screening techniques have been employed. ${ }^{[7]}$ For our investigation of polymerization reactions in water, we have utilized complexes based on the aforementioned known structures, and we varied the ligands to adjust their water solubility. ${ }^{[12 a]}$

Transition metal catalysis in aqueous media ${ }^{[8]}$ has been investigated intensely in the context of two-phase catalysis for the preparation of low molecular weight compounds. Due to the low miscibility of most organic substrates and products 
<smiles>[Y]C1=C([Y])[P+]([PH])(c2ccccc2)[N+]([3H])(P)O1</smiles>

1

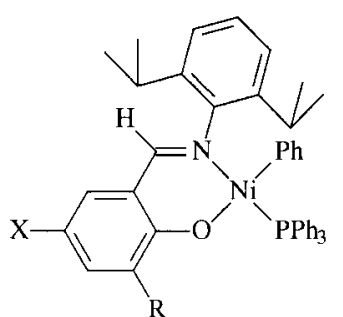

e.g.

$\mathrm{X}=\mathrm{H}, \mathrm{NO}_{2}$

$\mathrm{R}=\mathrm{H}$, aryl

activation of $\mathrm{PR}_{3}$ complexes for polymerization by phosphine scavengers

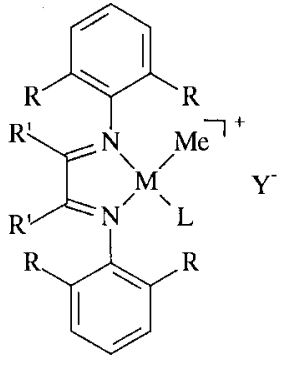

3

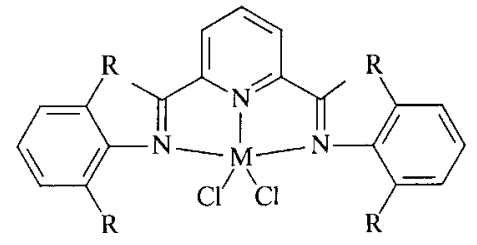

4

$\mathrm{M}=\mathrm{Fe}, \mathrm{Co}$

$\mathrm{R}=i \mathrm{Pr}, \mathrm{Me}$
$\mathrm{R}^{\prime}=\mathrm{Me}, \mathrm{H}$,

$\mathrm{R}=i \mathrm{Pr}, \mathrm{Me}$

$\mathrm{L}=\mathrm{OEt}_{2}, \mathrm{R}^{\prime \prime} \mathrm{CN}$

$\mathrm{Y}^{-}=\mathrm{BAr}_{4}^{\mathrm{F}-}, \mathrm{SbF}_{6}^{-}$

3a: $\mathrm{M}=\mathrm{Pd} ; \mathrm{Y}^{-}=\mathrm{SbF}_{6}{ }^{-}$;

$\mathrm{R}=\mathrm{R}^{\prime}=\mathrm{Me} ; \mathrm{L}=\mathrm{NCCH}_{3}$

Figure 1. Precursors to late transition metal catalysts for ethylene polymerization.

with water, the local concentrations of substrates at the catalytically active metal centers can differ markedly from reaction in organic solvents; this can result in strongly altered kinetics. Ethylene, employed as a substrate in our investigation, represents a somewhat particular case, as it does not form a separate bulk liquid phase under usual reaction conditions. With regard to the effect of water on the reactivity of the metal center, undesired side reactions of metal complexes with water can occur. Hydrolysis of metal-alkyl species, attack of water on coordinated substrates or on selectivity-controlling ligands, or coordination of water to the metal center as a ligand can be disadvantageous. ${ }^{[9]}$ For vinyltype aqueous coordination polymerization of olefins, the basic effects of reaction conditions on polymerization rate, catalyst stability, and the properties of the polymers obtained have thus far been given little attention.

A very slow (ca. one turnover/day) coordination polymerization of ethylene in water catalyzed by a rhodium complex has previously been investigated. ${ }^{[10,11]}$ Recently, homopolymerization of ethylene by cationic palladium(II) or neutral
nickel(II) catalysts in water as a reaction medium has been reported. ${ }^{[12]}$ Highly branched or linear polyethylenes can be obtained at high rates. We now give a first full account of such a coordination polymerization of ethylene in water and the properties of the resulting branched, amorphous polymers.

\section{Results and Discussion}

Polymerization reaction: If an aqueous suspension of complex $\mathbf{3} \mathbf{a}^{[5 a, 5 d]}$ is employed to polymerize ethylene, high molecular weight rubbery polyethylene is obtained. At higher ethylene pressures, polymerization rates of up to $900 \mathrm{TO} \mathrm{h}^{-1}$ are observed, similar to reaction in methylene chloride (vide infra). This is remarkable, as the solubility of ethylene in water (ca. $0.1 \mathrm{~mol} \mathrm{~L}^{-1}$ at $40 \mathrm{bar}$ ) is two orders of magnitude lower than the solubility in organic solvents such as toluene or methylene chloride. ${ }^{[13]}$ The low solubility of the olefinic monomer specific to polymerization reactions in water has received little systematic consideration in the few previous reports on other aqueous polymerization reactions by transition metal catalysts that employ ethylene as a monomer. An investigation of the effect of ethylene pressure on the aqueous polymerization revealed a large increase in activity with increasing ethylene pressure up to 20 bar (Table 1, Figure 2). Under these conditions, monomer concentration at the active metal centers must be controlling the rate of chain growth. Increasing the ethylene pressure from 20 to 40 bar has no strong effect, and this indicates that in this range the effective monomer concentration is no longer rate limiting. Thus, an effective polymerization is achieved at the rather moderate pressure of 20 bar. In contrast to this observed behavior in water, conventional polymerization in organic solvents is known to be approximately zero-order in ethylene with cationic diimine complexes, ${ }^{[5 a]}$ and also for the particular case of complex $\mathbf{3 a}$, no strong effect on activity is observed upon increasing the ethylene pressure from 2 to 50 bar for polymerization in solution in methylene chloride (Table 1, runs 4 to 6 ; Figure 2. In detail, some decrease in activity is observed at higher pressures; this effect has been observed previously $\left.{ }^{[\mathrm{d}]}\right)$. In terms of the basic steps of chain growth (Scheme 1), this known kinetic behavior translates to a predominant control of the overall chain growth rate by the rate of migratory insertion in the alkyl olefin intermediate (step a). In contrast, the observed behavior in aqueous polymerization can be rationalized by the fact that monomer coordination (step b) also strongly affects the rate of chain growth, due to low monomer concentrations at the metal site at pressures of less than approximately 20 bar. Based on these findings, it can be generalized that a high propensity of a complex coordination catalyst for binding of a monomer (step b) is advantageous for ethylene polymerization in water. By comparison, nickel(II) polymerization catalysts with a strong positive dependence of activity on ethylene concentration in polymerization in organic solvents also had a significantly lower activity for ethylene polymerization in water, compared with that for the reaction in toluene under the same conditions (50 bar ethylene pressure). ${ }^{[12 \mathrm{a}, 14]}$ Addition of surfactant under typical 
Table 1. Polymerization results. Reaction conditions: 3a $(61 \mu \mathrm{mol})$; room temperature; total volume of water or organic solvent: $100 \mathrm{~mL}$ $(-=$ not determined $)$.

\begin{tabular}{|c|c|c|c|c|c|c|c|c|}
\hline & & reaction conditions & & & & results & & \\
\hline & $\begin{array}{l}\text { ethylene } \\
\text { pressure } \\
\text { [bar] }\end{array}$ & $\begin{array}{l}\text { reaction } \\
\text { medium }\end{array}$ & $\begin{array}{l}\text { reaction } \\
\text { time } \\
{[\mathrm{h}]}\end{array}$ & $\begin{array}{l}\text { polymer } \\
\text { yield } \\
{[\mathrm{g}]}\end{array}$ & $\begin{array}{l}\text { productivity } \\
{\left[\left(\operatorname{mol}(\text { ethylene }) \operatorname{mol}(\text { cat. })^{-1}\right)\right]}\end{array}$ & $\begin{array}{l}\text { average activity } \\
{\left[\left(\operatorname{mol}(\text { ethylene }) \operatorname{mol}(\text { cat. })^{-1} h^{-1}\right)\right]}\end{array}$ & $\begin{array}{l}M_{\mathrm{w}}{ }^{[\mathrm{a}]} \\
{\left[\mathrm{g} \mathrm{mol}^{-1}\right]\left(M_{\mathrm{w}} / M_{\mathrm{n}}\right)}\end{array}$ & $\begin{array}{l}\text { branches } \\
\text { per } 1000 \mathrm{C}^{[\mathrm{b}]}\end{array}$ \\
\hline 1 & 2 & $\mathrm{H}_{2} \mathrm{O}$ & 16 & 3.5 & 2020 & 130 & $4.8 \times 10^{5}(3.5)$ & 71 \\
\hline 2 & 20 & $\mathrm{H}_{2} \mathrm{O}$ & 15 & 23.0 & 13400 & 900 & $4.1 \times 10^{5}(3.9)$ & 68 \\
\hline 3 & 40 & $\mathrm{H}_{2} \mathrm{O}$ & 3 & 2.3 & 1340 & 450 & $1.8 \times 10^{5}(2.8)$ & 64 \\
\hline 4 & 2 & $\mathrm{CH}_{2} \mathrm{Cl}_{2}$ & 16 & 29.2 & 17000 & 1100 & $3.8 \times 10^{4}(2.3)$ & 106 \\
\hline 6 & 50 & $\mathrm{CH}_{2} \mathrm{Cl}_{2}$ & 14 & 14.4 & 8400 & 600 & $3.2 \times 10^{4}(2.2)$ & 109 \\
\hline $7^{[\mathrm{c}]}$ & 7 & $\mathrm{H}_{2} \mathrm{O}$ (dial. tube) & 40 & 0.7 & 390 & 10 & $2.2 \times 10^{5}(3.0)$ & 77 \\
\hline $8^{[\mathrm{d}]}$ & 7 & gas phase & 4 & 0.8 & 470 & 120 & $1.1 \times 10^{5}(1.8)$ & 68 \\
\hline 9 & 40 & acetone & 14 & 11.7 & 6800 & 490 & $3.1 \times 10^{4}(2.4)$ & 94 \\
\hline
\end{tabular}

[a] Determined versus polystyrene standards. The molecular weights given can therefore differ substantially from the true molecular weight of these branched materials. However they allow for a comparison of the different samples, and represent the order of magnitude of the molecular weight. [b] Number of methyl groups per 1000 carbon atoms, determined by ${ }^{1} \mathrm{H}$ NMR in $\mathrm{CDCl}_{3}$ at room temperature. [c] Polymerization performed in dialysis tube. [d] Polymerization performed in gas phase.

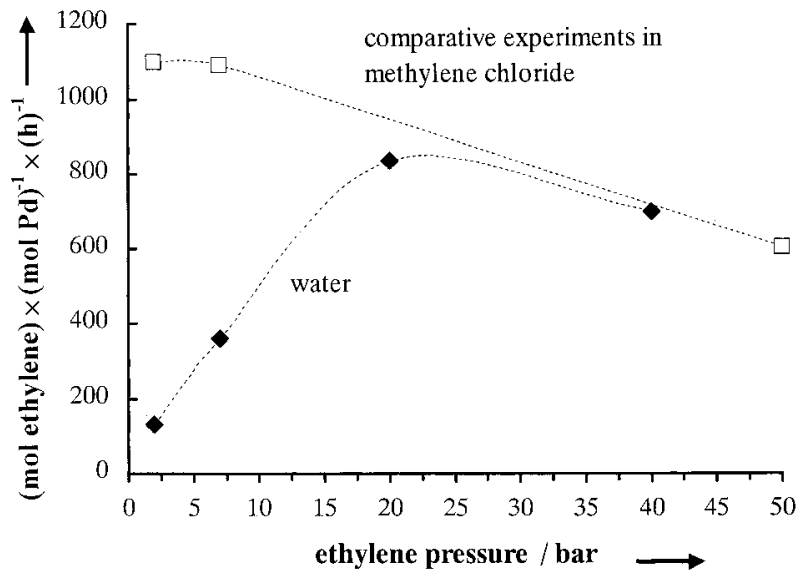

Figure 2. Polymerization activity versus ethylene pressure in water. Reaction conditions: catalyst precursor: 3 a ; reaction temperature: room temperature; reaction time: $15 \mathrm{~h}$. Data points are interconnected by lines for the sake of clarity.

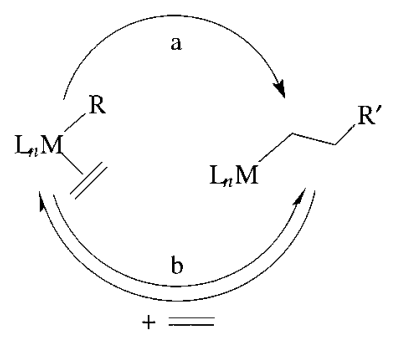

Scheme 1. Chain growth in ethylene polymerization $\left(\mathrm{R}, \mathrm{R}^{\prime}=\right.$ growing polymer chain).

polymerization conditions does not result in a dramatic increase in the amount of ethylene present in the liquid phase. ${ }^{[14]}$ Accordingly, addition of Triton X-100 nonionic surfactant $\left(0.01 \mathrm{~mol} \mathrm{~L}^{-1}\right.$, forty-fold critical micelle concentration) did not have a large effect on the polymerization rate.

The total amount of branching (as observed by NMR spectroscopy) as well as polymer molecular weights were found to be largely independent of ethylene pressure in aqueous polymerization reactions (Table 1$)$.
As previously mentioned, the polymerization reaction mixture is heterogeneous and consists of water, suspended polymer, and initially suspended 3a. With respect to the above considerations on ethylene solubility in water, the question arose whether polymerization might occur by direct transfer of ethylene to growing polymer particles at the gaswater interphase. Such a reaction would resemble a "watercooled" gas-phase polymerization rather than a suspensiontype polymerization in the aqueous phase. ${ }^{[15]}$ To gain insight into this question, polymerization reactions were carried out that avoided any contact of $\mathbf{3 a}$ or the polymer with the gas phase. In a typical experiment, 3 a was charged into a dialysis tube along with approximately $10 \mathrm{~mL}$ water, and the tube was then immersed completely in water in the glass reactor. The reactor was pressurized with ethylene, and the water phase was gently stirred with a stir bar to achieve some mass transfer and to avoid any generation of ethylene bubbles. Rubbery polyethylene confined in the dialysis tube was obtained (Table 1, entry 7). In experiments with different reaction times up to $67 \mathrm{~h}$, a steady activity of $10 \mathrm{TOh}^{-1}$ was observed. These results clearly demonstrate that polymerization also occurs without any direct contact of polymer or $\mathbf{3 a}$ with the gas phase. As expected, a lower productivity is observed in comparison with standard polymerization runs (vigorous mechanical stirring) due to slow diffusion through the dialysis tube and restricted transfer of ethylene from the gas phase to the aqueous phase (gentle stirring). Whilst it would be difficult to positively exclude the possibility of some degree of direct mass transfer of ethylene from the gas phase to the growing polymer particles in a simple practically useful polymerization setup, the above results unambiguously show that polymerization can occur by intermediate dissolution of ethylene in the water phase exclusively.

The reaction system consists of multiple phases: the gas phase, an aqueous phase that contains dissolved ethylene, suspended insoluble polymer swollen with monomer to some extent, and in the initial stages of the reaction solid undissolved complex $3 \mathbf{a}$. With regard to the ethylene concentration at the active metal sites in the polymer (vide supra), a consideration of ethylene solubility in the polymer is of 
interest. Data on ethylene - propylene random copolymers as amorphous saturated hydrocarbon polymers appear wellsuited for a comparison. For these polymers, ethylene solubility has been found to be insensitive to the ratio of incorporated ethylene/propylene, and thus the degree of branching over a wide range of compositions. ${ }^{[16]}$ The extrapolation of literature data to 20 bar yields a solubility on the order of $28 \mathrm{~g}$ ethylene/kg in the solid copolymer (approximately $\left.1 \mathrm{~mol} \mathrm{~L}^{-1}\right)$. By comparison, for polymerization in solution in methylene chloride (vide supra; Table 1, entries 4-6), a high rate of polymerization insensitive to ethylene concentration was observed at $\leq 2$ bar; this corresponds to $\leq 0.3 \mathrm{~mol} \mathrm{~L}^{-1}$. This order of magnitude estimate shows that ethylene solubility in amorphous polymers can be sufficient to attain monomer concentrations at which solution polymerizations with $\mathbf{3} \mathbf{a}$ are independent of monomer concentration, and this is in accordance with the aforementioned experimental observations. In heterogeneous aqueous polymerization, mass transfer of monomer across phase boundaries and within the polymer phase must obviously be considered in addition to thermodynamic equilibrium concentrations. ${ }^{[17]}$ The previously mentioned insensitivity of the aqueous polymerization reaction to ethylene pressure at $>20$ bar does not indicate mass transfer limitations. Reduction of the stirring rate from the standard $1000 \mathrm{rpm}$ to $400 \mathrm{rpm}$ resulted in a much less vigorous mixing of the reaction mixture. At a low ethylene pressure of $7 \mathrm{bar}$, a corresponding moderate decrease in activity of $20 \%$ was observed. This observation points to some limited influence of mass transfer in this regime.

To investigate the accessibility of the palladium complex for the aqueous phase during polymerization, a water-soluble, strongly coordinating deactivating reagent was added. To obtain meaningful results, a compound of high hydrophilicity that avoids any significant partial dissolution in the growing polymer must be employed. The addition of tris(sodium- $m$ sulfonatophenyl)phosphane (NaTPPTS) ${ }^{[18]}$ (ten equivalents) to an aqueous suspension of $\mathbf{3 a}$ in the polymerization reactor prior to pressurization with ethylene resulted in formation of a catalytically inactive solution. In contrast, the addition of NaTPPTS (ten equivalents) after one hour to an ongoing polymerization did not have a disadvantageous effect; when the reaction was continued for another $15 \mathrm{~h}, 15.8 \mathrm{~g}$ of polymer were obtained under the conditions of entry 3 ( 40 bar). This yield is only slightly lower than the amount of polymer obtained in the absence of phosphine (18.6 g). In comparison, upon addition of ten equivalents of triphenylphosphine to an ongoing solution polymerization in methylene chloride after one hour, complete catalyst deactivation was observed. These simple experiments reveal a strongly restricted accessibility of the palladium complex for the aqueous phase during the polymerization reaction. The catalytically active metal centers are confined, or "encapsulated" in the growing hydrophobic polymer.

Catalyst stability in water: To study catalyst stability, polymerization experiments with different reaction times were performed; a suspension of the catalyst precursor in water was employed (Figure 3). The polymer yields obtained at an

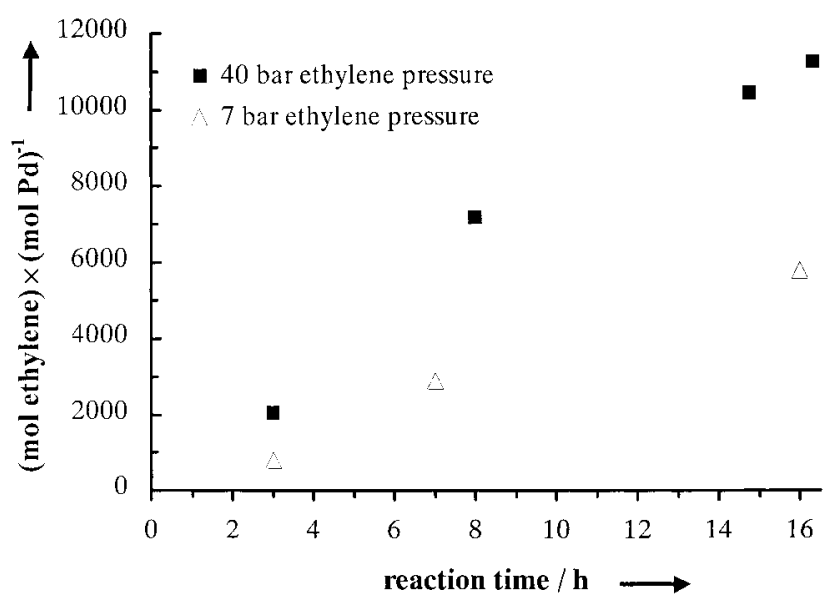

Figure 3. Productivity versus reaction time in aqueous ethylene polymerization. Reaction conditions: catalyst precursor: $3 \mathbf{a}$; reaction temperature: room temperature.

ethylene pressure of 40 or 7 bar correspond to an approximately steady activity over $16 \mathrm{~h}$. Thus, no catalyst deactivation is observed even for the long reaction times in this aqueous polymerization.

An investigation of the polymerization in acetone/water mixtures yielded unexpected results: addition of $5 \%$ water $(v / v)$ to an acetone reaction medium resulted in a large decrease in polymer yield (Figure 4). Upon increase of the water content, productivity ceased completely: no polymer or

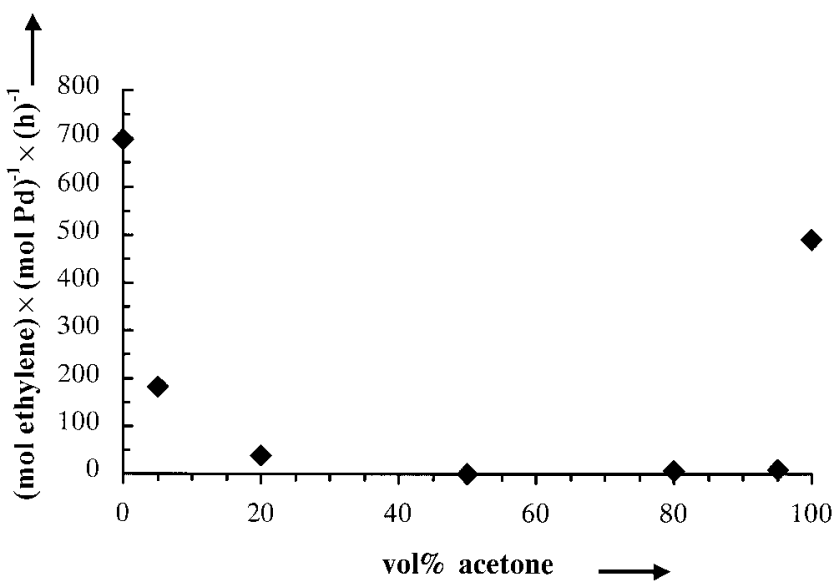

Figure 4. Polymerization productivity versus composition of acetone/ water reaction medium. Reaction conditions: catalyst precursor: 3a; reaction temperature: room temperature; ethylene pressure: $40 \mathrm{bar}$; reaction time: $15 \mathrm{~h}$

oligomers were obtained. This was somewhat surprising, as in polymerization in neat acetone (Table 1, entry 9) or water, similar high catalyst activities were observed. Only at high water contents of $>80 \%$ was catalytic productivity observed again. Whereas the catalyst precursor complex $\mathbf{3} \mathbf{a}$ is soluble in neat acetone or a 50:50 ( $/ / v)$ acetone/water mixture, it is insoluble in water or water that contains a small amount of organic solvent. Thus, the above experiments implied a rapid deactivation of the cationic palladium complex by water in solution. A water-soluble analogue 5 of complex $\mathbf{3 a}$ was prepared with the ligand $\mathrm{ArN}=\mathrm{C}(\mathrm{Me})-\mathrm{C}\left\{\left(\mathrm{CH}_{2}\right)_{4} \mathrm{SO}_{3} \mathrm{Li}\right\}=\mathrm{NAr}$ 
$\left(\mathrm{Ar}=2,6-\mathrm{C}_{6} \mathrm{H}_{3} \mathrm{Me}_{2}\right) \cdot{ }^{[19]}$ In accordance with the above conclusions, $\mathbf{5}$ did not display significant catalytic activity towards ethylene in aqueous solution (in comparison, a solution of $\mathbf{5}$ in methylene chloride displays a catalytic activity similar to $\mathbf{3 a}$ ).

For further investigation of the reactivity of the catalyst towards water, polymerizations were monitored by NMR spectroscopy. A ${ }^{1} \mathrm{H}$ NMR spectrum of a solution of catalyst precursor 3a in a $\left[\mathrm{D}_{6}\right]$ acetone $/ \mathrm{D}_{2} \mathrm{O} 3: 1(v / v)$ mixture was recorded, and the solution was stored at room temperature. Remarkably, a spectrum recorded after three days showed no changes; this demonstrated that the diimine-substituted palladium-methyl complex was stable under these conditions. ${ }^{[20]}$ However, upon addition of ethylene to the NMR tube, immediate formation of palladium black was observed, along with some chain growth. By comparison, upon addition of ethylene to a solution of $\mathbf{3 a}$ in neat $\left[D_{6}\right]$ acetone under identical conditions, no formation of elemental metal was observed. A Wacker-type attack of water on coordinated ethylene or decomposition of metal hydrides, which occur as intermediates in polymerization, could provide a reasonable explanation for these findings. Further studies of this deactivation reaction are in progress.

In summary, the high activity and catalyst stability in pure water or in water that contains only a small amount of organic solvent can be related to a low susceptibility for attack by water in the initial stages of polymerization due to the insolubility of $\mathbf{3 a}$. Polymerization occurs on catalyst particles, accompanied by a rapid encapsulation (vide supra) of the catalytically active palladium complex in the hydrophobic polymer. ${ }^{[21]}$

Polymer properties: The polyethylenes obtained in water resemble polymers obtained in methylene chloride as an aprotic solvent under otherwise identical conditions in that both are highly branched. However, the former have much higher molecular weights and are less branched, ${ }^{[22]}$ as determined by ${ }^{1} \mathrm{H}$ NMR spectroscopy (Table 1 ). These differences result in a markedly different macroscopic appearance of the polymers: whereas the materials obtained with $\mathbf{3 a}$ in methylene chloride are highly viscous liquids, polyethylenes obtained in water are rubbery solids. The question arose, whether the observed effect is due to an interaction of water with the metal center. The polymer microstructure was analyzed by high-temperature ${ }^{13} \mathrm{C}$ NMR spectroscopy (Table 2). Like the polyethylenes obtained in methylene chlor$\operatorname{ide}^{[23]}$ (Table 2, entry 2), the polymers obtained in water (Table 2, entry 1) contain methyl, ethyl, propyl, butyl, and higher branches. The occurrence of the same types of branches implies that basically the same mechanisms of chain growth, chain transfer, and chain walking are active. The overall polymer structure and the degree of branching will depend on the delicate balance of the reactivity of the various different intermediates involved in the last three reactions. It can be speculated that an increased steric constraint imposed on the catalyst confined in the solid polymer results in a lowering of chain transfer and chain walking, and this accounts for the lower degree of branching and higher molecular weight in comparison with polymerization in an organic solvent. ${ }^{[24]}$ A comparison with polymers obtained with this palladium catalyst in other, clearly heterogeneous reactions in the absence of water appeared interesting. Solid, finely dispersed 3a was exposed to 7 bar of ethylene in the absence of a liquid reaction medium. Although polymer yield was low in comparison with reactions in liquid dispersant, an amount of polymer sufficient for characterization was obtained (Table 1 , entry 8 ; Table 2 , entry 3 ). The overall branching of 68/1000 carbon atoms is similar to the material obtained in water as a reaction medium. Along the same lines, a polymerization was carried out in a fluorocarbon solvent (perfluorohexane), immiscible with the hydrocarbon polymer. Again, an overall degree of branching of 69/1000 carbon atoms was observed. These results imply that the formation of different polyethylenes in water and in conventional organic media is not related to an interaction of water with the catalytically active species, but rather to the different physical state of the reaction mixture during polymerization (heterogeneous suspension of catalyst-confining hydrophobic polymer vs. homogenous solution).

The thermal properties of the rubbery polymers were investigated by means of dynamic mechanical analysis (DMA). $T_{\mathrm{g}} \mathrm{s}$ of approximately $-45^{\circ} \mathrm{C}$ were observed. These glass transitions occur at markedly higher temperatures than those of polymers obtained in methylene chloride ( -69 to $-73^{\circ} \mathrm{C}$ obtained by DSC analysis (differential scanning calorimetry). DMA of these polymers is hampered by their liquid nature). DSC traces of polymers obtained in water reveal glass transition temperatures consistent with DMA results. In addition, in contrast to the polymers obtained in methylene chloride, broad thermal transitions in the range of +20 to $+60^{\circ} \mathrm{C}$ are observed. These transitions that indicate a very low degree of crystallinity were too weak for reliable quantitative assessment. Accordingly, by wide-angle X-ray scattering (WAXS), no significant reflections indicative of crystalline fractions were observed (limit of determination for polyethylene: $5-10 \%$ crystallinity).

The stress-strain behavior was investigated by cycle tests. The materials display good recovery, accompanied by some yield. Their behavior is qualitatively reminiscent of non-crosslinked thermoplastic polyolefin elastomers. ${ }^{[25]}$

Table 2. Branching structure of polymers determined by ${ }^{13} \mathrm{C}$ NMR spectroscopy. Polymers obtained at 40 bar (respectively, entry 3 : 7 bar) at ambient temperature.

\begin{tabular}{|c|c|c|c|c|c|c|c|c|}
\hline & $\begin{array}{l}\text { reaction } \\
\text { medium }\end{array}$ & $\begin{array}{l}\text { methyl } \\
\text { per } 1000 \mathrm{C} \text { atoms }\end{array}$ & $\begin{array}{l}\text { ethyl } \\
\text { per } 1000 \mathrm{C} \text { atoms }\end{array}$ & $\begin{array}{l}\text { propyl } \\
\text { per } 1000 \mathrm{C} \text { atoms }\end{array}$ & $\begin{array}{l}\text { butyl } \\
\text { per } 1000 \mathrm{C} \text { atoms }\end{array}$ & $\begin{array}{l}\text { pentyl } \\
\text { per } 1000 \mathrm{C} \text { atoms }\end{array}$ & $\begin{array}{l}\text { hexyl and longer } \\
\text { per } 1000 \mathrm{C} \text { atoms }\end{array}$ & $\begin{array}{l}\text { sum of branches } \\
\text { per } 1000 \mathrm{C} \text { atoms }\end{array}$ \\
\hline 1 & $\mathrm{H}_{2} \mathrm{O}$ & 29 & 10 & 3 & 5 & 4 & 14 & 65 \\
\hline 2 & $\mathrm{CH}_{2} \mathrm{Cl}_{2}$ & 34 & 28 & 4 & 8 & 4 & 27 & 105 \\
\hline 3 & gas phase & 27 & 10 & 4 & 5 & 5 & 15 & 66 \\
\hline
\end{tabular}




\section{Conclusion}

In the aqueous coordination polymerization of ethylene investigated, the rate of chain growth is controlled by the monomer concentration at the active site in the regime of ethylene pressures up to $20 \mathrm{bar}$. At higher pressures, the polymerization rate is not influenced significantly by the solubility of ethylene in the amorphous polyethylene or by mass transfer phenomena, but rather by the intrinsic kinetics of migratory insertion in alkyl-olefin complexes. As a generalization, a high propensity of a coordination catalyst for monomer binding is advantageous for polymerization of gaseous olefins in water as a reaction medium. Under appropriate conditions, mass transfer can occur exclusively by intermediate dissolution of ethylene in water, as opposed to conceivable direct mass transfer of ethylene from the gas phase to growing polymer particles.

Catalyst stability to water depends markedly on the physical state of the polymerization active metal complex in the initial stages of the reaction. An aqueous suspension of the precursor complex displays a high activity and stability; in contrast, solutions in acetone/water mixtures are inactive towards ethylene. The well-defined catalyst precursor complex is stable in solution, deactivation occurs only upon addition of ethylene monomer. During bulk polymerization, the catalytically active species is confined in the hydrophobic polymer, and this results in a strongly restricted accessibility for the aqueous phase.

The amorphous rubbery polyethylenes obtained differ from the viscous oils obtained in organic solvents under otherwise identical conditions by their much higher molecular weight and lower degree of branching. However, this effect is related to the different phase behavior during polymerization (suspension of nonsolvent swollen polymer vs. homogeneous solution) rather than an interaction of water with the polymerization active metal centers.

These findings represent the first extensive investigation and rationalization of a vinyl-type aqueous coordination polymerization reaction of a simple monoolefin.

\section{Experimental Section}

Materials and general considerations: Palladium complexes were manipulated by standard Schlenk techniques under argon. Ethylene $(99.8 \%)$ supplied by Gerling and Holz was used without further purification. Organic solvents were distilled from drying agents (acetone: $\mathrm{P}_{2} \mathrm{O}_{5}$, methylene chloride: $\mathrm{CaH}_{2}$ ) under argon. MilliQ grade water was briefly degassed prior to use. Palladium complex 3a was prepared according to literature procedures. ${ }^{[\mathrm{d}]}$

${ }^{1} \mathrm{H}$ and ${ }^{13} \mathrm{C}$ NMR spectra were recorded on a Bruker ARX 300 at $300 \mathrm{MHz}$ and $75 \mathrm{MHz}$, respectively. ${ }^{13} \mathrm{C}$ NMR spectra of polyethylenes were obtained in $\left[D_{2}\right] 1,1,2,2$-tetrachloroethane at $127^{\circ} \mathrm{C}$. Branching was determined according to ref. [26]. ${ }^{1} \mathrm{H}$ NMR spectra of the polymers were obtained in $\left[\mathrm{D}_{1}\right]$ chloroform at ambient temperature.

Dynamic mechanical analyses (DMA) were carried out on a Rheometrics Solids Analyzer RSA II at $1 \mathrm{~Hz}$ and a heating rate of $2 \mathrm{~K} \mathrm{~min}^{-1}$ using a dual cantilever geometry $(50 \times 6 \times 2 \mathrm{~mm})$. Differential scanning calorimetry (DSC) was performed on a Perkin ElmerDSC 7 at a heating rate of $10 \mathrm{~K} \mathrm{~min}^{-1}$. DSC data reported are second heats. High-temperature gel permeation chromatography was performed in 1,2,4-trichlorobenzene at $140^{\circ} \mathrm{C}$ using a PL-220 instrument equipped with MixedBed PL-columns.
Data reported were determined versus polystyrene standards. Wide-angle X-ray scattering (WAXS) was performed on a Siemens D 500 with a $2 \Theta$ distance of 0.1 and a measurement time of $6 \mathrm{~s}$ per point. Cycle tests were obtained on an Instron 4204 at ambient temperature with a velocity of $10 \mathrm{~mm} \mathrm{~min}^{-1}$. Specimens of dimension according to DIN 53504-85 S3 were prepared from melt-pressed sheets.

Polymerization procedure: Polymerization was carried out in a mechanically stirred pressure reactor $(250 \mathrm{~mL})$. Depending on the reaction pressure, a steel or glass vessel was utilized. The total volume of the added liquid phase (water and/or organic solvent) amounted to $100 \mathrm{~mL}$. For polymerization in water, complex $\mathbf{3} \mathbf{a}$ was injected as a solution in acetone $(1.5 \mathrm{~mL})$ to achieve a fine suspension of the water-insoluble catalyst precursor. The reactor was flushed with ethylene, and a constant ethylene pressure was applied, while the reaction mixture was stirred (1000 rpm). After the specified reaction time, the reaction was stopped by releasing the ethylene pressure. The precipitated polymers were isolated, washed with water and methanol, and dried in vacuum.

NMR data of complex $3 \mathrm{a}$ in acetone/water mixtures: ${ }^{1} \mathrm{H}$ NMR $(300 \mathrm{MHz}$ $\left[\mathrm{D}_{6}\right]$ acetone, room temperature, TMS): $\delta=0.25\left(\mathrm{~s}, 3 \mathrm{H} ; \mathrm{PdCH}_{3}\right), 2.07(\mathrm{~s}$, $\left.3 \mathrm{H} ; \mathrm{NCCH}_{3}\right), 2.27$ (s, broad, $\left.6 \mathrm{H} ; \mathrm{N}=\mathrm{C}\left(\mathrm{CH}_{3}\right)-\mathrm{C}^{\prime}\left(\mathrm{CH}_{3}\right)=\mathrm{N}\right), 2.34(\mathrm{~s}, 6 \mathrm{H}$; $\left.\mathrm{Ar}-\mathrm{CH}_{3}\right), 2.38\left(\mathrm{~s}, 6 \mathrm{H} ; \mathrm{Ar}-\mathrm{CH}_{3}\right), 7.18-7.29(\mathrm{~m}, 6 \mathrm{H} ; \mathrm{Ar}-\mathrm{H}) ;{ }^{1} \mathrm{H}$ NMR $\left(300 \mathrm{MHz},\left[\mathrm{D}_{6}\right.\right.$ ]acetone/ $\mathrm{D}_{2} \mathrm{O} 3: 1(\mathrm{v} / \mathrm{v})$, room temperature, TMS): $\delta=0.24$ $\left(\mathrm{s}, 3 \mathrm{H} ; \mathrm{PdCH}_{3}\right), 2.06\left(\mathrm{~s}\right.$, broad, $\left.3 \mathrm{H} ; \mathrm{NCCH}_{3}\right), 2.27\left(\mathrm{~s}, 6 \mathrm{H} ; \mathrm{Ar}-\mathrm{CH}_{3}\right), 2.32(\mathrm{~s}$, broad, $\left.6 \mathrm{H} ; \mathrm{N}=\mathrm{C}\left(\mathrm{CH}_{3}\right)-\mathrm{C}^{\prime}\left(\mathrm{CH}_{3}\right)=\mathrm{N}\right), 2.34\left(\mathrm{~s}, 6 \mathrm{H} ; \mathrm{Ar}-\mathrm{CH}_{3}\right), 7.20-7.30(\mathrm{~m}$, $6 \mathrm{H} ; \mathrm{Ar}-\mathrm{H})$.

\section{Acknowledgements}

The authors thank R. Mülhaupt for his generous support. Financial support by BASF AG is gratefully acknowledged. A.H. thanks the Deutsche Forschungsgemeinschaft for a Graduiertenkolleg stipend. A generous loan of palladium chloride was provided by Degussa-Huels. We thank M. Morath for excellent technical assistance and F. Weiss and S. Kniesel for participation in this research as part of their undergraduate studies. Skillful assistance in NMR and GPC experiments by A. Hasenhindl and U. Westphal is gratefully acknowledged.

[1] a) Emulsion Polymerization and Emulsion Polymers (Eds.: P. A. Lovell, M. S. El-Aasser), Wiley, Chichester, 1997; b) Wäßrige Polymerdispersionen (Ed.: D. Distler), VCH, Weinheim, 1999; c) G. Lagaly, O. Schulz, R. Zimehl, Dispersionen und Emulsionen, Steinkopff, Darmstadt, 1997.

[2] a) Ziegler Catalysts (Eds.: G. Fink, R. Mülhaupt, H. H. Brintzinger), Springer, Berlin, 1995; b) H. H. Brintzinger, D. Fischer, R. Mülhaupt, B. Rieger, R. Waymouth, Angew. Chem. 1995, 107, 1255; Angew. Chem. Int. Ed. Engl. 1995, 34,1143; c) G. J. P. Britovsek, V. C. Gibson, D. F. Wass, Angew. Chem. 1999, 111, 448; Angew. Chem. Int. Ed. 1999, 38, 428; d) W. Kaminsky, M. Arndt, Adv. Polym. Sci. 1997, 127, 143.

[3] a) G. Wilke, Angew. Chem. 1988, 100, 189; Angew. Chem. Int. Ed. Engl. 1988, 27, 185; b) M. Peuckert, W. Keim, Organometallics 1983, 2, 594

[4] S,O ligands: a) R. Bauer, H. Chung, G. Cannell, W. Keim, H. van Zwet (Shell), US 3637636, 1972; [Chem. Abstr. 1971, 75, 130322r]; N,N: b) W. Keim, R. Appel, A. Storeck, C. Krueger, R. Goddard, Angew. Chem. 1981, 93, 91; Angew. Chem. Int. Ed. Engl. 1981, 20, 116 (for the related reaction of $\alpha$-olefins cf. V. M. Moehring, G. Fink, Angew. Chem. 1985, 97, 982; Angew. Chem. Int. Ed. Engl. 1985, 24, 1001); c) W. Keim, Ann. N.Y. Acad. Sci. 1983, 415, 191; P,O: d) W. Keim, F. H. Kowaldt, R. Goddard, C. Krueger, Angew. Chem. 1978, 90, 493; Angew. Chem. Int. Ed. Engl. 1978, 17, 466; e) K. A. Ostoja-Starzewski, J. Witte, Angew. Chem. 1987, 99, 76; Angew. Chem. Int. Ed. Engl. 1987, 26, 63; f) K. A. Ostoja-Starzewski, J. Witte, K. H. Reichert, G. Vasiliou in Transition Metals and Organometallics as Catalysts for Olefin Polymerization (Eds.: W. Kaminsky, H. Sinn), Springer, Berlin, 1988, p. 349; g) U. Klabunde, S. D. Ittel, J. Mol. Cat. 1987, 41, 123; N,O: h) C. Wang, S. Friedrich, T. R. Younkin, R. T. Li, R. H. Grubbs, D. A. Bansleben, M. W. Day, Organometallics 1998, 17, 3149; i) L. K. Johnson, A. M. A. Bennett, S. D. Ittel, L. Wang, A. Parthasarathy, 
E. Hauptman, R. D. Simpson, J. Feldman, E. B. Coughlin (DuPont), WO98/30609, 1998; [Chem. Abstr. 1998, 129, 149362j]; j) T. R. Younkin, E. F. Connor, J. I. Henderson, S. K. Friedrich, R. H. Grubbs, D. A. Bansleben, Science 2000, 287, 460.

[5] Ni, Pd: a) L. K. Johnson, C. M. Killian, M. Brookhart, J. Am. Chem. Soc. 1995, 117, 6414; b) L. K. Johnson, S. Mecking, M. Brookhart, J. Am. Chem. Soc. 1996, 118, 267; c) C. M. Killian, D. J. Tempel, L. K. Johnson, M. Brookhart, J. Am. Chem. Soc. 1996, 118, 11664; d) S. Mecking, L. K. Johnson, L. Wang, M. Brookhart, J. Am. Chem. Soc. 1998, 120, 888; e) L. K. Johnson, C. M. Killian, S. D. Arthur, J. Feldman, E. McCord, S. J. McLain, K. A. Kreutzer, M. A. Bennett, E. B. Coughlin, S. D. Ittel, A. Parthasarathy, D. Tempel, M. Brookhart (UNC-Chapel Hill/DuPont), WO96/23010, 1996; [Chem. Abstr. 1996 125, 222773 t]; Co, Fe: f) B. L. Small, M. Brookhart, A. M. A. Bennett, J. Am. Chem. Soc. 1998, 120, 4049; g) G. J. P. Britovsek, V. Gibson, B. S. Kimberley, P. J. Maddox, S. J. McTavish, G. A. Solan, A. J. P. White, D. J. Williams, Chem. Commun. 1998, 849; h) A. M. A. Bennett (DuPont), WO98/27124, 1998; [Chem. Abstr. 1998, 129, $122973 \mathrm{x}]$.

[6] Reviews on late transition metal catalyzed olefin polymerization: a) see ref. [2c]; b) S. Mecking, Coord. Chem. Rev. 2000, 203, 325; c) S. D. Ittel, L. K. Johnson, M. Brookhart, Chem. Rev. 2000, 100, 1169 .

[7] B. Jandeleit, D. J. Schaefer, T. S. Powers, H. W. Turner, W. H. Weinberg, Angew. Chem. 1999, 111, 2648; Angew. Chem. Int. Ed. 1999, 38, 2476.

[8] Aqueous-Phase Organometallic Chemistry (Eds.: B. Cornils, W. A. Herrmann), VCH, Weinheim, 1998.

[9] W. A. Herrmann in Aqueous-Phase Organometallic Chemistry (Eds.: B. Cornils, W. A. Herrmann), VCH, Weinheim, 1998, p. 35.

[10] L. Wang, R. S. Lu, R. Bau, T. C. Flood, J. Am. Chem. Soc. 1993, 115, 6999.

[11] For other transition metal catalyzed olefin polymerization reactions in water cf. the following leading references. Butadiene polymerization: a) R. E. Rinehart, H. P. Smith, H. S. Witt, H. Romeyn, J. Am. Chem. Soc. 1961, 83, 4864; b) A. J. Canale, W. A. Hewett, T. M. Shryne, E. A. Youngman, Chem. Ind. 1962, 1054; c) R. E. Rinehart, H. P. Smith, H. S. Witt, H. Romeyn, J. Am. Chem. Soc. 1962, 84, 4145; ROMP (ring opening metathesis polymerization): d) B. M. Novak, R. H. Grubbs, $J$. Am. Chem. Soc. 1988, 110, 7542; e) D. M. Lynn, B. Mohr, R. H. Grubbs, J. Am. Chem. Soc. 1998, 120, 1627; f) B. Mohr, D. M. Lynn, R. H. Grubbs, Organometallics 1996, 15, 4317; Other cycloolefin polymerizations: g) R. E. Rinehart, J. Polym. Sci. Part C 1969, 27, 7; h) G. Natta, G. Dall'Asta, L. Porri, Makromol. Chem. 1965, 81, 253; Alternating olefin-CO copolymerization: i) Z. Jiang, A. Sen, Macromolecules 1994, 27, 7215; j) G. Verspui, G. Papadogianakis, R. A. Sheldon, Chem. Commun. 1998, 401; k) C. Bianchini, H. Man Lee, A. Meli, S. Moneti, V. Patinec, G. Petrucci, F. Vizza, Macromolecules 1999, 32, 3859; 1) G. Verspui, J. Feiken, G. Papadogianakis, R. A. Sheldon, J. Mol. Catal. 1999, 146, 299; m) G. Verspui, F. Schanssema, R. A. Sheldon, Angew. Chem. 2000, 112, 825; Angew. Chem. Int. Ed. 2000, 39, 804; Also cf. n) W. Reppe, A. Magin, US 2577208, 1948.

[12] a) A. Held, F. M. Bauers, S. Mecking, Chem. Commun. 2000, 301; b) A. Tomov, J.-P. Broyer, R. Spitz, Macromol. Symp. 2000, 150, 53; c) For previous notes on the stability of cationic palladium diimine polymerization catalysts towards air and moisture, cf. ref. [5b, 5d]. For a previous example of an ethylene polymerization in water with the catalyst described in ref. [5a-5d], carried out by S. J. McLain, cf. ref. [5e].

[13] Ethylene solubility was determined experimentally according to the method reported in ref. [5d] and [14]. The data obtained are in good agreement with values calculated according to: U. Plöcker, H. Knapp,
J. Prausnitz, Ind. Eng. Chem. Process Des. Dev. 1978, 17, 324; (Data kindly provided by J. Suhm, BASF AG).

[14] F. M. Bauers, Diploma thesis, Albert-Ludwigs-Universität Freiburg (Germany), 2000.

[15] The terms suspension, dispersion, and emulsion polymerization have been coined for free-radical polymerizations (cf. e.g. ref. [1c]). For the application of these terms to coordination polymerization, it must be kept in mind that these reactions occur by different basic modes of chain growth and chain transfer, which will influence the mechanisms of particle formation and growth. The term suspension-type polymerization seems appropriate here in that the polymer precipitates during the reaction.

[16] a) J.-S. Yoon, C.-Y. Chung, I.-H. Lee, Eur. Polym. J. 1994, 30, 1209. Further background information also cf. b) G. J. van Amerongen, Rubber Chem. Technol. 1964, 37, 1065; c) D. W. van Krevelen, Properties of Polymers: Their Correlation with Chemical Structure; Their Numerical Estimation and Prediction from Additive Group Contributions, Elsevier, Amsterdam, 1994, p. 535.

[17] In the context of this discussion, it should be noted that even for somewhat simpler systems (gas; two immiscible liquid phases) of commercial interest, a full understanding of all mass transfer phenomena and the exact location of the reaction site has proven to be difficult to obtain: P. Claus, M. Baerns in Aqueous-Phase Organometallic Chemistry (Eds.: B. Cornils, W. A. Herrmann), VCH, Weinheim, 1998, p. 151.

[18] a) E. G. Kuntz, CHEMTECH 1987, 17, 570; b) E. G. Kuntz (RhonePoulenc), FR2314910, 1975; [Chem. Abstr. 1977, 87, 101944n].

[19] A. Held, S. Mecking, unpublished results. The ligand $\operatorname{ArN}=\mathrm{C}$ $(\mathrm{Me})-\mathrm{C}\left\{\left(\mathrm{CH}_{2}\right)_{4} \mathrm{SO}_{3} \mathrm{Li}\right\}=\mathrm{NAr}\left(\mathrm{Ar}=2,6-\mathrm{C}_{6} \mathrm{H}_{3} \mathrm{Me}_{2}\right)$ was obtained by deprotonation of $\mathrm{ArN}=\mathrm{C}(\mathrm{Me})-\mathrm{C}(\mathrm{Me})=\mathrm{NAr}$ with lithium diisopropylamide and subsequent ring opening of 1,3-propanesultone in THF in $80 \%$ yield.

[20] For recent notes on the stability of other isolated cationic palladium(II) methyl complexes in the presence of water cf: M. A. Zuideveld, P. C. J. Kamer, P. W. N. M. van Leeuwen, P. A. A. Klusener, H. A. Stil, C. F. Roobek, J. Am. Chem. Soc. 1998, 120, 7977, and ref. [11m].

[21] It can be assumed that the primary particles of the catalyst precursor break up during polymerization, in a somewhat similar way to the olefin polymerization by supported commercial Ziegler-type catalysts.

[22] Ethylene homopolymers with similar overall branching to the polymers obtained in water can be prepared using cationic nickel complexes. However, these polymers possess a markedly different microstructure, strongly dominated by methyl branches: a) ref. [5a]; b) J. Heinemann, P. Walter, D. Mäder, R. Schnell, J. Suhm, R. Mülhaupt in Metalorganic Catalysts for Synthesis and Polymerization (Ed.: W. Kaminsky), Springer, Berlin/Heidelberg, 1999, p. 473.

[23] Z. Guan, P. M. Cotts, E. F. McCord, S. J. McLain, Science 1999, 283, 2059.

[24] Chain transfer is known to occur via sterically demanding fivecoordinate intermediates. Also, formation of secondary alkyls, necessary for branching to occur, will result in an increased steric bulk at the metal center.

25] C.-K. Shih, A. C. L. Lu in Thermoplastic Elastomers-A Comprehensive Review (Eds.: N. R. Legge, G. Holden, H. E. Schroeder), Hanser, München, 1987, p. 91.

[26] a) J. C. Randall, J. Macromol. Sci. Rev. Macromol. Chem. Phys. 1989, C29, 201; b) D. E. Axelson, G. C. Levy, L. Mandelkern, Macromolecules 1979, 12, 41; c) see ref. [5e]. 